\title{
Photosystem II: The Water-Splitting Enzyme of Photosynthesis
}

\author{
J. BARBER \\ Division of Biomolecular Sciences, Department of Life Sciences, \\ Imperial College London, SW7 2AZ, United Kingdom \\ Correspondence: j.barber@imperial.ac.uk
}

\begin{abstract}
The oxygen in our atmosphere is derived and maintained by the water-splitting process of photosynthesis. The enzyme that facilitates this reaction and therefore underpins virtually all life on our planet is known as photosystem II (PSII), a multisubunit enzyme embedded in the lipid environment of the thylakoid membranes of plants, algae, and cyanobacteria. During the past 10 years, crystal structures of a 700-kDa cyanobacterial dimeric PSII complex have been reported with ever-increasing improvement in resolution - the latest at $1.9 \AA$. Thus, the organizational and structural details of its many subunits and cofactors are now well understood. The water-splitting site was revealed as a cluster of four $\mathrm{Mn}$ ions and one Ca ion surrounded by aminoacid side chains, of which seven provide ligands to the metals. The metal cluster is organized as a cubane-like structure composed of three $\mathrm{Mn}$ ions and the one $\mathrm{Ca}^{2+}$ ion linked by oxo bonds. The fourth $\mathrm{Mn}$ is attached to the cubane via one of its bridging oxygens together with another oxo bridge to an $\mathrm{Mn}$ ion of the cubane. The overall structure of the catalytic site provides a framework to propose a mechanistic scheme for the water-splitting process and gives a blueprint for the development of catalysts that mimick the reaction in an artificial chemical system as a means to generate solar fuels.
\end{abstract}

Somewhere in the region of 2.5 billion years ago, an enzyme emerged that would dramatically change the chemical composition of our planet and set in motion an unprecedented explosion in biological activity. This enzyme used solar energy to power the thermodynamically and chemically demanding reaction of water splitting. In so doing, it provided biology with an unlimited supply of hydrogen equivalents needed to convert carbon dioxide into the organic molecules of life. Before this, biological organisms had been dependent on hydrogen/ electron donors such as $\mathrm{H}_{2} \mathrm{~S}, \mathrm{NH}_{3}$, organic acids, and $\mathrm{Fe}^{2+}$, which were in limited supply compared with the "oceans" of water with which planet Earth is blessed. The by-product of the water-splitting reaction is molecular oxygen. The release of this gas also had dramatic consequences for the development of life: It created an oxygenic atmosphere and at the same time allowed the ozone layer to form. With oxygen available, the efficiency of cellular metabolism increased dramatically because for a given amount of substrate, aerobic respiration provides in the region of 15 times more energy than anaerobic respiration. It was probably this improved efficiency of cellular bioenergetics that paved the way for the subsequent evolution of eukaryotic cells and multicellular organisms. The establishment of the ozone layer provided a shield against harmful ultraviolet radiation, allowing organisms to prosper and diversify on an enormous scale, as testified by fossil records and the extent and variety of the living organisms on our planet today. The enzyme that gave rise to this "big bang of evolution" is known as photosystem II (PSII) and is truly the engine of life (Barber 2003).

\section{PHOTOSYSTEM II}

PSII is a multisubunit protein complex located in the thylakoid membranes of all types of plants, algae, and cyanobacteria (Fig. 1) (Barber 2003). At its heart is the reaction center $(\mathrm{RC})$ core, where light energy is converted to electrochemical potential energy and where the watersplitting reaction occurs. The PSIIRC core consists of two homologous proteins, D1 and D2, and two further closely related chlorophyll (Chl)-containing proteins (CPs), CP43 and CP47. The former pair has five (A-E), and the latter pair six (I-VI), transmembrane helices. There are also a number of other low-molecular-mass transmembrane subunits that are rather featureless except for two that bind the high-potential heme of cytochrome b559 (Cyt b559). Finally, the PSIIRC core complex contains several extrinsic proteins attached to its lumenal surface that form a protein shield over the catalytic site of water splitting. Although one of these proteins, PsbO, is ubiquitous to all oxygenic photosynthetic organisms, the others vary among different types of organisms. Plants and green algae bind PsbP and PsbQ proteins, whereas PsbU and PsbV proteins are only found in red algae and cynanobacteria (De Las Rivas et al. 2004). Other extrinsic proteins are transiently bound during the life cycle of PSII. This core complex is serviced by an outer light-harvesting system that, in the case of plants and green algae, is composed of intrinsic Lhcb proteins that bind Chl $a$ and Chl $b$ as shown in Figure 1. In red algae and cyanobacteria, this outer antenna is replaced by phycobiliproteins comprising the phycobilisome bound extrinsically to the stromal surface of the PSII core. 


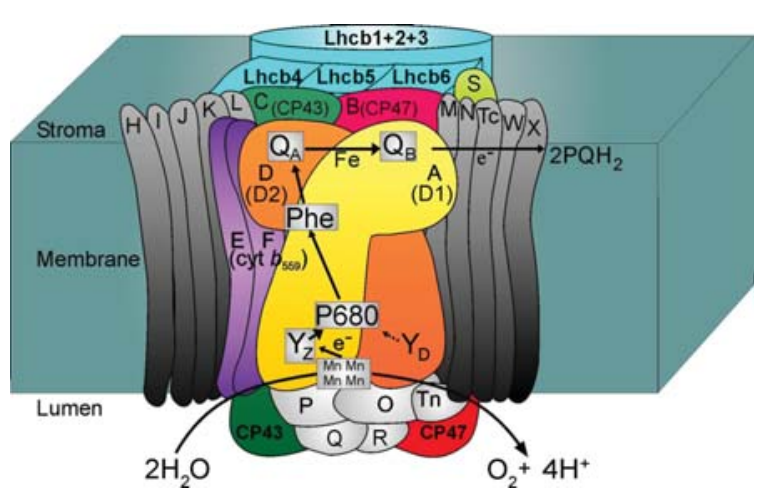

Figure 1. Illustration of the structure and subunit composition of PSII of higher plants and green algae. Intrinsic and extrinsic proteins are labeled according to the gene nomenclature in Table 1 (e.g., psbA = A), with common nomenclature given for the major subunits (e.g., A = D1 protein). (Light green) Outer lightharvesting $\mathrm{Chl} \mathrm{a/Chl} \mathrm{b-binding} \mathrm{proteins} \mathrm{(intrinsic} \mathrm{Lhcb/Cab}$ proteins). (Arrows) Electron transfer pathway from water oxidation to plastoquinone reduction (see text).

The way in which PSII uses light energy to generate an electrochemical potential in the form of a charge transfer state is essentially the same as that for other types of photosynthetic systems. Chl molecules and other pigments (e.g., $\beta$-carotene) absorb visible light and transfer the excitations to a reaction center where charge separation occurs. The striking difference is that in the case of PSII, the oxidizing "hole" left by charge separation is highly oxidative and used to drive water splitting. All of the redox-active cofactors involved in the energy conversion process are bound to D1 and D2 proteins and the following sequence of reactions occurs (see Fig. 2A): A special form of Chl $a$, P680 (P), acts as an exciton trap and is converted to a strong reducing agent after excitation $\left(\mathrm{P}^{*}\right) . \mathrm{P}^{*}$ reduces a pheophytin $a$ molecule (Pheo) in a few picoseconds to form the radical pair state $\mathrm{P}^{+} \mathrm{Pheo}{ }^{-}$. Within a few hundred picoseconds, $\mathrm{Pheo}^{-}$reduces a firmly bound plastoquinone molecule $\mathrm{PQ}_{\mathrm{A}}\left(\mathrm{Q}_{\mathrm{A}}\right)$ to produce $\mathrm{P}^{+}$PheoQ $\mathrm{A}_{\mathrm{A}}^{-}$. $\mathrm{P}^{+}$, with its very high redox potential $(>1 \mathrm{~V})$, oxidizes a tyrosine residue $\operatorname{Tyr}_{Z}\left(\mathrm{Y}_{Z}\right)$ to form $\mathrm{Tyr}_{Z}+\mathrm{PPheoQ}_{\mathrm{A}}^{-}$on a nanosecond time scale. Try $\mathrm{Z}_{\mathrm{Z}}^{+}$is deprotonated to form a neutral radical $\mathrm{Thr}_{Z}^{\circ}$. In the millisecond time domain, $\mathrm{Q}_{\mathrm{A}}^{-}$reduces a second plastoquinone $\mathrm{PQ}_{\mathrm{B}}\left(\mathrm{Q}_{\mathrm{B}}\right)$ to form $\mathrm{Tyr}^{\bullet} \mathrm{PPheo}_{\mathrm{A}} \mathrm{Q}_{\mathrm{B}}^{-}$, and at about the same time, $\mathrm{Tyr}^{\bullet}$ extracts an electron from a cluster of four $\mathrm{Mn}$ atoms that bind the two substrate water molecules. A second photochemical turnover reduces $\mathrm{Q}_{\mathrm{B}}^{-}$to $\mathrm{Q}_{\mathrm{B}}^{2-}$, which is then protonated to plastoquinol $\mathrm{PQH}_{2}$ and released from the $\mathrm{Q}_{\mathrm{B}}$-binding site of PSII into the lipid bilayer, where it is subsequently oxidized by photosystem I (PSI) via the cytochrome $b_{6} f$ complex. Two further photochemical turnovers provide a cluster of four $\mathrm{Mn}$ ions and one $\mathrm{Ca}$ ion $\left(\mathrm{Mn}_{4} \mathrm{Ca}^{2+}\right)$, with a total of four oxidizing equivalents that are used to oxidize two water molecules to form dioxygen. Each oxidation state generated within the oxygen-evolving complex (OEC) is represented as an intermediate of the S-state cycle (Kok et al. 1970 ), of which there are at least five $\left(S_{0}-S_{4}\right)$ (see Fig. $2 \mathrm{~A})$. In addition to these reactions, side reactions can occur under some conditions including the oxidation of Cyt b559, a $\beta$-carotene molecule, and a Chl $a$ molecule. These side reactions occur on a tens of milliseconds time scale and therefore do not compete with the electron transfer pathway leading to water oxidation. Indeed, they probably only occur when the rate of water oxidation becomes limited and thus provide a protective mechanism against the detrimental reactions resulting from the very high redox potential of the long-lived $\mathrm{P} 680$ radical cation $\left(\mathrm{P}^{+}\right)$(Stewart and Brudvig 1998).

As with studies of other enzymes, the reactions of PSII cannot be fully understood in molecular terms without a detailed knowledge of its structure. Many techniques give structural information at different degrees of complexity, but none match the overall level of detail gained from Xray-diffraction analysis. PSII is a membrane protein complex, making it more difficult to crystallize. Nevertheless,
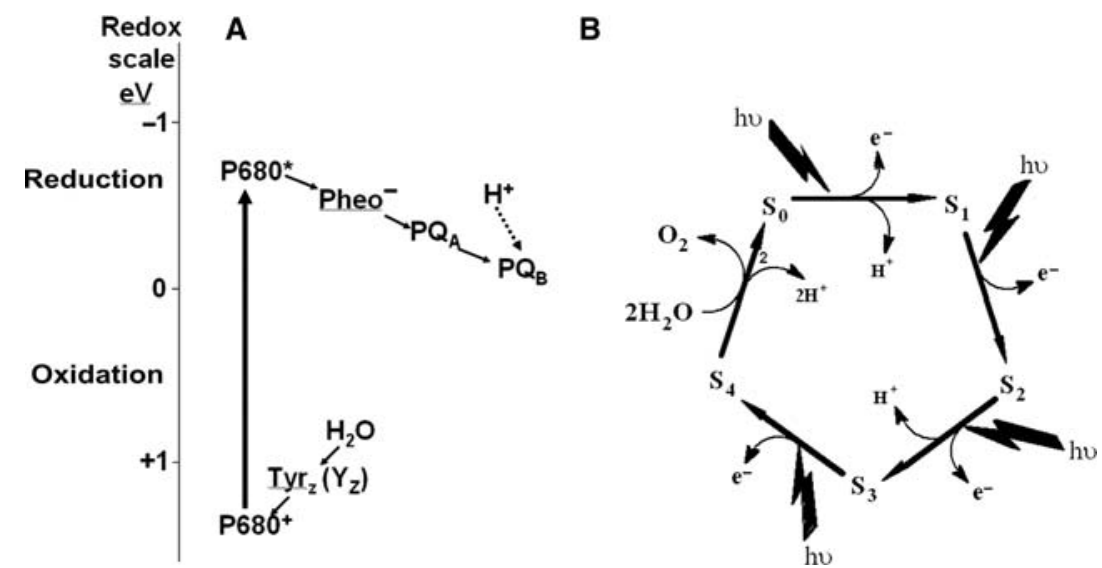

Figure 2. $(A)$ Diagram of energy level for light-induced electron transfer in PSII from water oxidation to the plastoquinone $\left(\mathrm{PQ}_{\mathrm{B}}\right)$ reduction. $(B) \mathrm{S}$-state cycle shows how the absorption of four photons of light (hv) drives the splitting of two water molecules and the formation of $\mathrm{O}_{2}$ through a consecutive series of five intermediates $\left(\mathrm{S}_{0}, \mathrm{~S}_{1}, \mathrm{~S}_{2}, \mathrm{~S}_{3}\right.$, and $\left.\mathrm{S}_{4}\right)$. Protons $\left(\mathrm{H}^{+}\right)$are released into the lumen during this cycle, except for the $S_{1}$ to $S_{2}$ transition, and electrons are donated to $\mathrm{P}_{680}^{+}$via the redox-active $\operatorname{Tyr}_{Z}\left(\mathrm{Y}_{Z}\right.$ in Fig. 1). 
progress during the past 10 years has been substantial and is the focus of this report. The structural information obtained has improved our understanding of the many reactions of PSII and most importantly, the water-splitting reaction itself, knowledge that has far-reaching implications in the development of new technologies for the production of fuel.

\section{CRYSTAL STRUCTURE OF PSII}

\section{Proteins}

The first X-ray-derived structure of PSII used a preparation isolated from the cyanobacterium Thermosynechococcus elongatus and was elucidated by Zouni et al. (2001). Their structure was limited to a resolution of 3.8 $\AA$, and the $\mathrm{C}-\alpha$ backbones of many of the subunits were not fully traced. Although no side-chain positioning was deduced, their model confirmed the dimeric organization of the isolated complex (see Hankamer et al. 1997) and the relative positioning of the major subunits and their transmembrane helices within each monomer derived from electron crystallography (Rhee et al. 1998; Hankamer et al. 2001a,b). It also provided information on the positioning of cofactors involved in excitation transfer and charge separation. Most importantly, the analysis of the diffraction data gave the first direct structural hints of the Mn cluster of the OEC. Two years later, Kamiya and Shen (2003) reported a 3.7- $\AA$ crystal structure of PSII isolated from Thermosynechococcus vulcanus, a cyanobacterium closely related to $T$. elongatus, and provided additional information to that revealed by Zouni et al. (2001). The tracing of the $\mathrm{C}-\alpha$ backbones was more complete and some effort was made to assign a few amino acids, particularly those of D1 and D2 proteins as well as to assign some to regions of the chlorophyll-binding proteins CP43 and CP47. However, it was not until the work of Ferreira et al. (2004) that all of the protein subunits of PSII were assigned and their structures revealed. The PSII complex crystallized was isolated from T. elongatus and its X-raydiffraction-derived structure was refined to a resolution of $3.5 \AA$. More than 5000 amino acids (close to $100 \%$ of this huge complex) were mapped within the dimeric complex, thus revealing for the first time the protein environments of all of the major cofactors as well as assigning the location of 18 of the 19 subunits that made up each monomer. As a consequence, a host of outstanding questions were answered, not least of which was direct evidence that the phenolic group of $\mathrm{Thr}_{\mathrm{Z}}$ (D1Tyr161) is $\mathrm{H}$ bonded to nearby D1His190, a necessary requirement for this redoxactive tyrosine to function in electron transfer between P680 and the $\mathrm{Mn}_{4} \mathrm{Ca}^{2+}$ cluster. In addition, the finding that glutamate 354 of CP43 (CP43Glu354) was a ligand to the $\mathrm{Mn}_{4} \mathrm{Ca}^{2+}$ cluster highlighted another striking discovery among many others.

The side view of the PSIIRC dimeric core complex of T. elongatus shown in Figure $3 \mathrm{~A}$ is taken from the crystal structure of Ferreira et al. (2004). The PSII dimer has dimensions of $105-\AA$ depth $(45 \AA$ in spanning the membrane), 205- $\AA$ length, and 110- $\AA$ width and has a calculated total molecular mass of $\sim 700 \mathrm{kDa}$. In total, there are 35 transmembrane helices per monomer, and these are depicted as cylinders in Figure 1A. Details of the 19 different subunits are highlighted in Table 1, with one subunit, Ycf12 (originally suggested to possibly be PsbN), included based on more recent biochemical analysis of PSII (Kashino et al. 2007) and confirmed by the 1.9-^ crystal structure (Umena et al. 2011). Note that the other nonhighlighted proteins in Table 1 are exclusive to the PSII core complex of higher plants.

The three extrinsic proteins PsbO, PsbU, and PsbV form a cap over the catalytic site where oxygen evolution occurs, preventing access by reductants other than water. Some of the low-molecular-mass subunits are located on the periphery of the CP43/D1/D2/CP47 cluster, where they likely help to stabilize the binding of $\mathrm{Chl}$ and $\beta$ carotene molecules contained within the complex. The exceptions to this are PsbE and PsbF proteins, which provide histidine ligands for the heme of Cyt b559, and the PsbL, PsbM, and PsbT proteins located at the monomer-monomer interface where they possibly have a role in stabilizing the dimeric nature of the PSII complex. All of the small subunits have a single transmembrane helix except for PsbZ, which has two (see Table 1). Subsequent X-ray models of cyanobacterial PSII by Loll et al. (2005), Guskov et al. (2009), and Umena et al. (2011) agreed with the assignments of the small subunits made by Ferreira et al. (2004), with 1.9 $\AA$ confirming the location of Ycf12 adjacent to PsbK and PsbZ. The 2.9- $\AA$ crystal structure of Guskov et al. (2009) contained an additional transmembrane helix assigned to PsbY, but this peripheral subunit was absent in the structures of Ferreira et al. (2004) and Umena et al. (2011).

All of the crystal structures of PSII confirmed that the transmembrane helices of D1 and D2 proteins are arranged in an almost identical way to those of the $\mathrm{L}$ and $\mathrm{M}$ subunits of the purple bacterial RC as anticipated by homology (Barber 1987; Michel and Deisenhofer 1988). The six transmembrane helices of CP43 and CP47 are arranged in three pairs around a pseudo-threefold axis, as first shown by electron crystallography (Rhee et al. 1997, 1998). These two Chl-binding proteins are located on each side of the D1 and D2 subunits in such a way that their transmembrane helices are related by the same pseudo-twofold axis that relates the five transmembrane helices of the D1/D2 heterodimer, an organization very similar to that of the RC core of PSI (Schubert et al. 1998; Murray et al. 2006). Both are characterized as having a very large extrinsic loop joining the lumenal ends of helices V and VI.

\section{Cofactors}

Chlorophylls and Carotenoids. The Ferreira et al. (2004) structural analysis identified per monomer 36 Chls and tentatively assigned seven carotenoids, assumed to be all trans $\beta$ carotene ( $\beta$-Car). It was concluded that CP43 and CP47 bound 14 and 16 Chl $a$ molecules, respectively, and in the majority of cases, these light- 

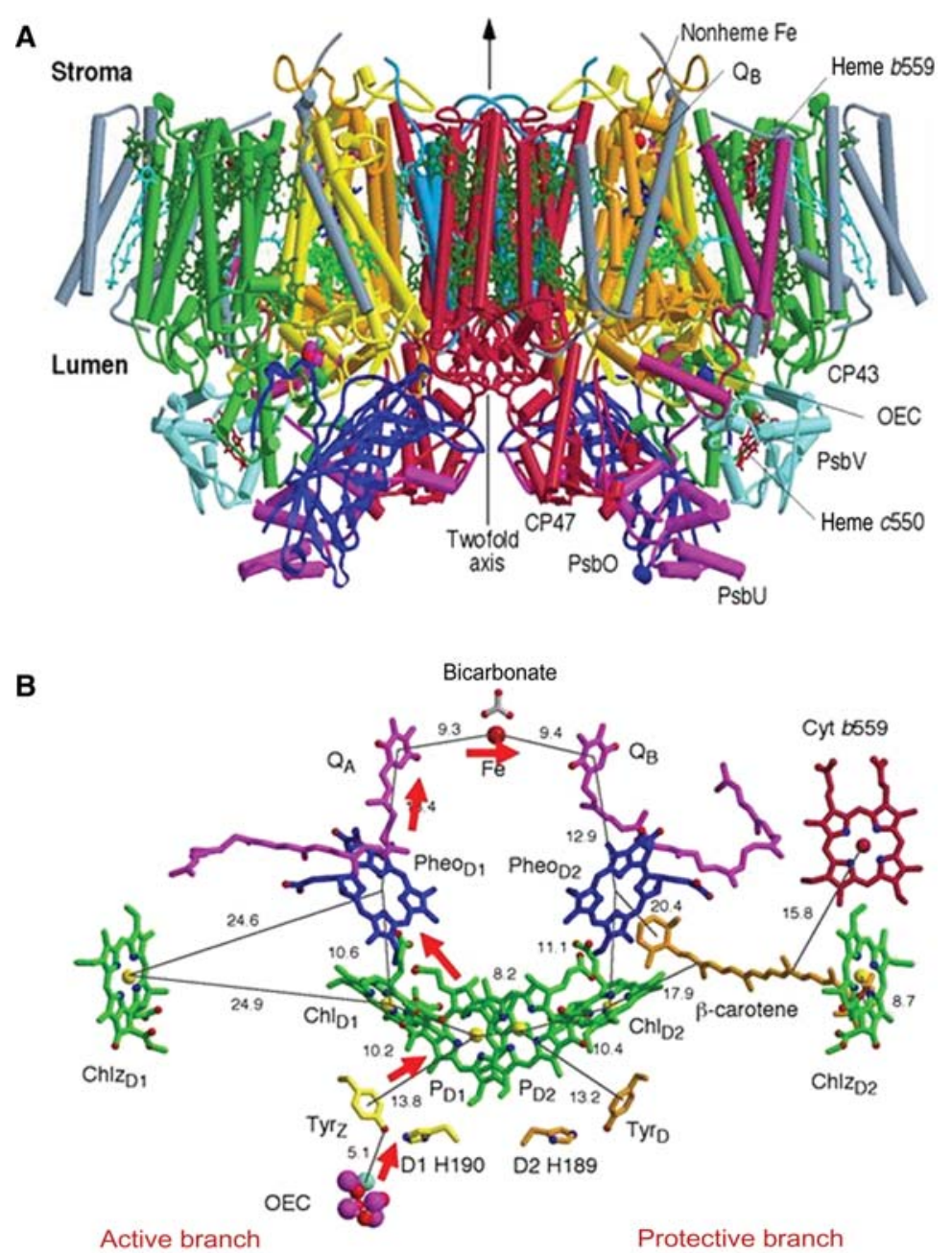

Figure 3. (A) Side view of the structure of photosystem II, the water-splitting enzyme of photosynthesis. Structure was determined using X-ray crystallography (Ferreira et al. 2004). The complex, embedded in the thylakoid membrane spanning their lumenal and stromal surfaces, is composed of two monomers related to each other by a twofold axis. Each monomer contains 19 different protein subunits. Sixteen are located with the membrane matrix and have $\alpha$ helices (depicted by cylinders). In total, there are 35 transmembrane helices per monomer. D1 and D2 proteins that comprise the reaction center are shown in yellow and orange, respectively. The $\mathrm{Mn}_{3} \mathrm{Ca}$ catalytic center of the OEC is located on the lumenal side of the complex and is stabilized and shielded by three extrinsic proteins: PsbO, PsbU, and PsbV. (B) Organization of the electron transfer cofactors that comprise the reaction center of photosystem II as revealed by X-ray crystallography (Ferreira et al. 2004). Excitation of the reaction center via the chlorophylls (Chl) (green) leads to the reduction of pheophytin (Pheo), resulting in the formation of the radical pair $\mathrm{P} 680^{+} \mathrm{Pheo}^{-}$. The radical cation of $\mathrm{P} 680$ is localized on $\mathrm{P}_{\mathrm{D} 1}$, whereas the radical anion is located on $\mathrm{Pheo}_{\mathrm{D} 1}$. The electron on $\mathrm{Pheo}_{\mathrm{D} 1}^{-}$is rapidly donated to a firmly bound plastoquinone $\mathrm{Q}_{\mathrm{A}}$ (purple) and then transferred to a second plastoquinone $\mathrm{Q}_{\mathrm{B}}$ (also purple). This electron transfer is aided by the presence of a nonheme iron located midway between them. When the $\mathrm{Q}_{\mathrm{B}}$ plastoquinone has been doubly reduced and protonated, the resultant plastoquinol $\left(\mathrm{PQH}_{2}\right)$ diffuses from the $\mathrm{Q}_{\mathrm{B}}$-binding site into the lipid matrix of the membrane, and $\mathrm{P} 60^{+}$is reduced by a redox-active tyrosine $\left(\mathrm{Tyr}_{\mathrm{Z}}\right)$ that then extracts electrons from the $\mathrm{Mn}_{4} \mathrm{Ca}$ cluster; that constitutes the OEC. These electron transfer processes occur mainly on the D1 side of the reaction center, (red arrow). Some of the symmetrically related cofactors located on the D2 side (Pheo 2 ) are nonfunctional. Other cofactors on the D2 side (heme of cytochrome $b 559$ [red], the $\beta$-carotene molecule [brown], and Chl $z_{\mathrm{D} 2}$ ), however, are functionally active and seem to have a role in protecting PSII against photo-induced damage. ( $A$, Reprinted, with permission, from Ferreira et al. 2004. (C)AAAS.)

harvesting Chls were ligated by either $\alpha$ or $\beta$ linkages to conserved histidine side chains and related by the same pseudo-twofold symmetry axis that relate their transmembrane helices. The Chls were arranged in layers toward the lumenal and stromal surfaces, with one $\mathrm{Chl}$ in each case located midway between the layers. Remarkably, the majority of the Chls bound to CP43 and CP47 have counterparts bound in the amino-terminal domains of the PsaA and PsaB RC proteins of PSI (Murray et al.
2006). The more recent crystal structures of cyanobacterial PSII at 2.9- and 1.9- $\AA$ resolution have extended and corrected Ferreira et al.'s assignment of seven $\beta$-Car molecules to 11 all trans $\beta$-Cars and concluded that CP43 binds $13 \mathrm{Chls}$ rather than 14 . The higher-resolution crystal structures also confirmed that the D1/D2 heterodimer bound six symmetrically related Chls, as detailed earlier (Zouni et al. 2001; Kamiya and Shen 2003; Ferreira et al. 2004), but extended Ferreira et al.'s assignment of $\beta$-Car 
Table 1. Gene nomenclature

\begin{tabular}{|c|c|c|c|}
\hline Gene & Subunit & Mass $(\mathrm{kDa})$ & $\begin{array}{c}\text { Number of } \\
\text { transmembrane } \\
\alpha \text { helices }\end{array}$ \\
\hline$p s b \mathrm{~A}(\mathrm{c})$ & D1 & $38.021(\mathrm{~S})$ & 5 \\
\hline$p s b \mathrm{~B}(\mathrm{c})$ & CP47 & $56.278(\mathrm{~S})$ & 6 \\
\hline$p s b C(c)$ & CР43 & $50.066(\mathrm{~S})$ & 6 \\
\hline$p s b \mathrm{D}(\mathrm{c})$ & D2 & 39.418 (S) & 5 \\
\hline psbE (c) & $\alpha$-cyt b559 & $9.255(\mathrm{~S})$ & 1 \\
\hline psbF (c) & $\beta$-cyt b559 & 4.409 (S) & 1 \\
\hline$p s b \mathbf{H}(\mathbf{c})$ & H protein & $7.697(\mathrm{~S})$ & 1 \\
\hline psbI (c) & I protein & $4.195(\mathrm{~S})$ & 1 \\
\hline psbJ (c) & $\mathbf{J}$ protein & $4.116(\mathrm{P})$ & 1 \\
\hline$p s b \mathrm{~K}(\mathrm{c})$ & K protein & $4.283(\mathrm{~S})$ & 1 \\
\hline$p s b \mathrm{~L}$ (c) & L protein & $4.366(\mathrm{~S})$ & 1 \\
\hline$p s b M(c)$ & M protein & $3.755(\mathrm{P})$ & 1 \\
\hline$p s b \mathrm{~N}$ (c) & $\mathrm{N}$ protein & $4.722(\mathrm{~T})$ & 1 \\
\hline$p s b \mathrm{O}(\mathrm{c})$ & $33-\mathrm{kDa} O$ protein & $26.539(\mathrm{~S})$ & 0 \\
\hline$p s b \mathrm{P}(\mathrm{n})$ & 23-kDa P protein & $20.210(\mathrm{~S})$ & 0 \\
\hline $\operatorname{psb} \mathrm{Q}(\mathrm{n})$ & $16-\mathrm{kDa} Q$ protein & $16.523(\mathrm{~S})$ & 0 \\
\hline$p s b \mathrm{R}(\mathrm{n})$ & $\mathrm{R}$ protein & $10.236(\mathrm{~S})$ & 0 \\
\hline$s b \mathrm{~S}(\mathrm{n})$ & $\mathrm{S}$ protein & $29.197(\mathrm{~S})$ & 4 \\
\hline$p s b \mathrm{~T}$ (c) & $\mathbf{T}_{\mathbf{C}}$ protein & $3.849(\mathrm{~S})$ & 1 \\
\hline$p s b \mathrm{~T}(\mathrm{n})$ & $\mathrm{T}_{\mathrm{n}}$ protein & $5.000(\mathrm{~A})$ & 0 \\
\hline$p s b \mathrm{U}$ & U protein & 10.491 (Sy) & 0 \\
\hline$p s b \mathrm{~V}$ & $\mathrm{~V}$ protein & 15.121 (Sy) & 0 \\
\hline$p s b \mathrm{~W}(\mathrm{n})$ & W protein & $5.928(\mathrm{~S})$ & 1 \\
\hline $\operatorname{psbX}(\mathrm{n})$ & $\mathrm{X}$ protein & $4.225(\mathrm{~S})$ & 1 \\
\hline psbY (c) & Y protein & 4.202 (Sy) & 1 \\
\hline$p s b Z$ (c) & $\mathrm{Z}$ protein & $6.541(\mathrm{~S})$ & 2 \\
\hline ycf 12 & Ycf protein & 4.143 (Sy) & 1 \\
\hline
\end{tabular}

from one located within the D2 protein to a second on the D1 side of the heterodimer.

A very important contribution of the most recent PSII crystal structure (Umena et al. 2011) is that it was at sufficient resolution to identify the location of 2795 water molecules in the dimeric complex. Most of these water molecules form two layers at the stromal and lumenal surfaces. However, a few molecules are located in the membrane-spanning region of the complex, with seven acting as ligands to the $\mathrm{Mg}$ of Chls, which are not ligated by amino acids (these are histidines in all cases except one, where CP43Asn39 is a ligand). Water ligands were found for the two accessory Chls $\left(\mathrm{Chl}_{\mathrm{D} 1}\right.$ and $\left.\mathrm{Chl}_{\mathrm{D} 2}\right)$ of the D1/D2 heterodimer, as originally suggested by Ferreira et al. (2004), whereas the others are for three Chls of CP47 and two Chls of CP43. Umena et al. (2011) noted that most of the vinyl groups of the CP43 and CP47 Chls are positioned in or near the same plane of the tetrapyrrole ring, which would be expected to facilitate energy migration among adjacent chlorophylls. Whereas the role of the Chls and $\beta$-Car bound to CP43 and CP47 is to capture photons and transfer excitation to the reaction center, $\beta$-Car has an additional function, namely, to quench harmful $\mathrm{Chl}$ triplet states and any singlet oxygen that might be generated. For Chl triplet quenching, they must be located close to the porphyrin head group of Chl, and this is borne out in the crystal structures. The only exceptions are the two $\beta$-Car molecules bound to the D1/D2 heterodimer, where their role seems to be as electron transfer agents and possibly as singlet oxygen quenchers.
Redox-Active Cofactors. The D1 and D2 proteins bind the cofactors that bring about charge separation leading to the oxidation of water and reduction of the terminal electron/proton plastoquinone acceptor $\mathrm{Q}_{\mathrm{B}}$. Together, they bind six Chl $a$, two Pheo, two plastoquinones (PQs), two $\beta$-Cars, and a nonheme Fe. The Ferreira et al. (2004) crystal structure and those reported by others (Zouni et al. 2001; Kamiya and Shen 2003) clearly showed that these cofactors are arranged around the same pseudo-twofold axis that relates the transmembrane helices of D1, D2, CP43, and CP47 (see Fig. 3B). The axis passes through the nonheme Fe and through the middle of a cluster of four Chl $a$ molecules $\left(\mathrm{P}_{\mathrm{D} 1}, \mathrm{P}_{\mathrm{D} 2}, \mathrm{Chl}_{\mathrm{D} 1}\right.$, and $\left.\mathrm{Chl}_{\mathrm{D} 2}\right)$, where the suffix denotes binding to the D1 and D2 proteins. Similarly, the two pheophytins are referred to as $\mathrm{Pheo}_{\mathrm{D} 1}$ and $\mathrm{Pheo}_{\mathrm{D} 2} \cdot \mathrm{Q}_{\mathrm{A}}$ and $\mathrm{Q}_{\mathrm{B}}$ are positioned equally on each side of the nonheme $\mathrm{Fe}$ and are bound to sites located within the D2 and D1 proteins, respectively. The remaining two Chls $\left(\mathrm{Chlz}_{\mathrm{D} 1}\right.$ and $\left.\mathrm{Chlz}_{\mathrm{D} 2}\right)$ are also symmetrically related, being ligated to histidines located in the B-transmembrane helices of D1 and D2 proteins.

Photons are captured by the light-harvesting pigments and transferred, as excitation energy, via the Chls of CP43 and $\mathrm{CP} 47$ to the $\mathrm{P}_{\mathrm{D} 1} / \mathrm{P}_{\mathrm{D} 2} / \mathrm{Chl}_{\mathrm{D} 1} / \mathrm{Ch}_{\mathrm{D} 2}$ cluster. Although $\mathrm{P}_{\mathrm{D} 1}$ and $\mathrm{P}_{\mathrm{D} 2}$ are located adjacent to each other, excitonic interaction between their tetrapyrolle head groups is weak, and they do not form a "special pair," as found in other types of reaction centers. Moreover, the recent highresolution structure (Umena et al. 2011) has shown that $\mathrm{P}_{\mathrm{D} 1}$ and $\mathrm{P}_{\mathrm{D} 2}$ are not perfectly symmetry related because the vinyl group of $\mathrm{P}_{\mathrm{D} 1}$ is approximately in the plane of the membrane with its terminal carboxyl atom close to the Mg of $\mathrm{P}_{\mathrm{D} 2}$, whereas the $\mathrm{P}_{\mathrm{D} 2}$ vinyl group is out of the chlorin plane and is not located close to the Mn of $\mathrm{P}_{\mathrm{D} 1}$. The monomeric character of $\mathrm{P}_{\mathrm{D} 1}$ and $\mathrm{P}_{\mathrm{D} 2}$ makes them approximately isoenergetic with each other and with the two accessory Chls, $\mathrm{Chl}_{\mathrm{D} 1}$ and $\mathrm{Chl}_{\mathrm{D} 2}$. Indeed, according to the 1.9- $\AA$ structure (Umena et al. 2011) the $\pi-\pi$ and $\mathrm{CH}$ $\pi$ stacking ranges from 3.3 to $3.5 \AA$, with the shortest distance between $\mathrm{P}_{\mathrm{D} 1}$ and $\mathrm{Chl}_{\mathrm{D} 1}$. Therefore, it seems that excitation energy arriving at this cluster is delocalized over all four Chls to form the $\mathrm{P}^{*}$ state (Durrant et al. 1995). The initial electron transfer probably occurs from $\mathrm{Chl}_{\mathrm{D} 1}$ because it is the closest to $\mathrm{PheO}_{\mathrm{D} 1}$ to form the charge transfer state $\mathrm{Chl}_{\mathrm{D} 1}^{+} \mathrm{PheO}_{\mathrm{D} 1}^{-}$(Holzwarth et al. 2006). This radical pair state is short lived, with migration of the "hole" to $\mathrm{P}_{\mathrm{D} 1}$ to form $\mathrm{P}_{\mathrm{D} 1}^{+} \mathrm{Pheo}{ }^{-}$, where $\mathrm{P}_{\mathrm{D} 1}^{+}$corresponds to the long-lived $\mathrm{P}$ radical cation (Barber and Archer 2001).

The electron on $\mathrm{PheO}_{\mathrm{D} 1}$ then proceeds down the thermodynamic gradient to the terminal PQ electron acceptor bound to the $\mathrm{Q}_{\mathrm{B}}$ site within the $\mathrm{D} 1$ protein. As mentioned earlier, this electron transfer occurs within a few milliseconds and is aided by a fast intermediate electron transfer from $\mathrm{Pheo}^{-}$to the $\mathrm{PQ}$ bound in the $\mathrm{Q}_{\mathrm{A}}$ site of the $\mathrm{D} 2$ protein and by the nonheme Fe midway between $Q_{A}$ and $\mathrm{Q}_{\mathrm{B}}$. After receiving two electrons, PQ is protonated to plastoquinol $\mathrm{PQH}_{2}$ and leaves the PSII complex by detachment from the $\mathrm{Q}_{\mathrm{B}}$ site. A channel leading from the $\mathrm{Q}_{\mathrm{B}}$ site has been identified (Loll et al. 2005; Murray and Barber 2007). This quinone/quinol diffusion channel 
exits between the subunits of Cyt b559 and PsbJ and is coated with the phytol chains of several Chls and acyl chains of lipids as well as the close proximity of two carotenoids, thus imposing a high degree of lipophylicity. A second potential quinone channel has been postulated that is based on the assignment of a third PQ molecule in the 2.9- $\AA$ PSII structure refined by Guskov et al. (2009). However, this additional PQ molecule was not identified in the 1.9- $\AA$ structure of Umena et al. (2011).

The reduction of $\mathrm{P}_{\mathrm{D} 1}^{+}$is brought about by removing an electron from the OEC, thus driving an Mn ion of the $\mathrm{Mn}_{4}-\mathrm{Ca}^{2+}$ cluster into a higher-oxidation state. This electron transfer process is aided by a redox-active Tryz (D1Tyr161). This tyrosine has a symmetrically related counterpart within the D2 protein, $\operatorname{Tyr}_{\mathrm{D}}$ (see Fig. 2) that can also be oxidized by $\mathrm{P}_{\mathrm{D} 1}^{+}$but is not directly involved in the water-splitting reaction. It may, however, because of its long lifetime help to direct primary charge separation to the D1 side of the RC by electrostatic biasing (Faller et al. 2001). This symmetrical relationship ends here because the $\mathrm{Mn}_{4} \mathrm{Ca}$ cluster is only located on the D1 side and the heme of Cyt b559 is located on the D2 side. Therefore, the D1 side of the RC functions directly in energy conversion and water splitting, whereas the D2 side is, in part, involved in protection against photoinduced damage.

Despite the symmetric arrangement of cofactors on the reducing side, electron transport from $\mathrm{P}_{\mathrm{D} 1}$ to $\mathrm{Q}_{\mathrm{B}}$ involves only $\mathrm{Pheo}_{\mathrm{D} 1}$, whereas the other possible route via $\mathrm{Pheo}_{\mathrm{D} 2}$ does not occur - a situation also found for electron transfer in the reaction centers of purple photosynthetic bacteria (Rutherford 1989). In fact, the arrangement of cofactors on the reducing side of PSII is essentially identical to that of their bacterial counterparts. The only clear exceptions are that one of the ligands for the nonheme Fe of PSII is a bicarbonate ion and not a glutamate, as in bacteria, and the $\mathrm{Q}_{\mathrm{B}}$ site is a little larger and in closer contact with the stromal surface than in the bacterial RC. That bicarbonate provides a bidentate ligand for the nonheme Fe that has been known for some time (Hienerwadel and Berthomieu 1995), and the assignment by Ferreira et al. (2004) has been confirmed in the $1.9-\AA$ crystal structure (Umena et al. 2011). Its function is unclear but its removal slows the kinetics of $\mathrm{Q}_{\mathrm{A}}$ to $\mathrm{Q}_{\mathrm{B}}$ electron transfer and may therefore represent a feedback mechanism from $\mathrm{CO}_{2}$ fixation to regulate PSII activity (Govindjee and van Rensen 1993).

Cyt $b 559$ has high midpoint potential of $+0.4 \mathrm{~V}$ and is therefore ideally poised to act as an electron donor $\mathrm{P}_{\mathrm{D} 1}^{+}(\mathrm{E}$ $\sim 1.2 \mathrm{~V}$ ) and an electron acceptor from the reduced plastoquinone in the $\mathrm{Q}_{\mathrm{B}}$ site $(\mathrm{E} \sim 0 \mathrm{~V})$. This cyclic electron transfer does not normally compete with the water oxidation reactions, having kinetics in the millisecond timescale, and is only relevant when the very oxidizing $\mathrm{P}_{\mathrm{D} 1}^{+}$ state becomes long lived and therefore potentially dangerous. Because of the large spatial separation between Cyt $b 559$ and $\mathrm{P}_{\mathrm{D} 1}^{+}$, electron flow from the heme to primary donor is aided by the $\beta$-Car identified by Ferreira et al. (2004) that is positioned strategically between them (see Fig. 3B). The two peripheral $\mathrm{Chlz}_{\mathrm{D} 1}$ and
$\mathrm{Chlz}_{\mathrm{D} 2}$ also show redox activity and similarly act to protect the buildup of long-lived $\mathrm{P}_{\mathrm{D} 1}^{+}$states. Again, $\beta$-Car on the D1 and D2 sides would be required to facilitate the long-range electron transfer to $\mathrm{P}_{\mathrm{D} 1}^{+}$.

Lipids and Detergents. The first attempts to assign lipid and detergent molecules in the crystal structure of PSII was made by Loll et al. (2005). They assigned 14 lipids within the monomer: four digalactosyl-diacylglycerol (DGDG), six monogalactosyl-diacylglycerol (MGDG), three sulphoquinovosyl-diacylglycerol (SQDG), one phosphatidyl-glycerol (PG), and three detergent molecules $(\beta-$ dodecyl maltoside, used for isolating the complex).

This assignment was further refined by Guskov et al. (2009), raising the total to 25 (seven DGDG, 11 MGDG, five SQDG, two PG) and eight $\beta$-dodecyl maltoside molecules. The high lipid content is very unusual for a membrane protein complex and possibly relates to the fact that the D1 protein turns over regularly due to light-induced damage (Barber and Andersson 1992). It was noted that the charged lipids (SQDG and PG) are exclusively located at the outer stromal surface, whereas the neutral DGDG and MGDG were located at both surfaces. Assigning specific lipids and detergents using 3.0 to $2.9 \AA$ data is difficult, and it is not surprising that the $1.9-\AA$ crystal structure significantly modified the original assignments to five DGDG, six MGDG, four SQDG, five PG, and more than $15 \beta$-dodecyl maltoside molecules, with further refinement required to assign additional densities that are either lipid or detergent.

$\mathbf{M n}_{4}$-Ca Cluster. The 3.8-^ X-ray-diffraction data generated from crystals of PSII isolated from T. elongatus and analyzed by Zouni et al. (2001) provided hints of the position of the $\mathrm{Mn}_{4}$ cluster within the complex. The electron density assigned to the metal cluster was consistent with four Mn ions based on anomalous diffraction data collected at $1.894 \AA$ and was found to be toward the lumenal surface of PSII on the D1 side of the pseudotwofold axis of the RC. The electron density had a "pear shape" having dimensions of $6.8 \AA \times 4.9 \AA \times 3.3 \AA$, with its longest axis tilted at $\sim 23^{\circ}$ to the membrane plane. Because of the low resolution and the fact that the model was incomplete, including the absence of side-chain positioning, the assignment of the four Mn ions within the density was rather arbitrary. A Mn ion was positioned in the three bulges of the "pear-shaped" density to form an isosceles triangle, with a fourth $\mathrm{Mn}$ ion placed in the center of the triangle. The $3+1$ organization of the four $\mathrm{Mn}$ ions gave support to the arrangement previously suggested by Peloquin et al. (2000) and earlier by Hasegawa et al. (1999) and was also a feature of the crystallographic model of the Mn cluster derived by Kamiya and Shen (2003). However, Kamiya and Shen modeled the four Mn ions so that they were approximately in the same plane, whereas Zouni et al. (2001) had placed the central Mn ion protruding toward the lumenal surface. Importantly, Kamiya and Shen's map contained electron density connecting to that of the Mn cluster that was tentatively assigned to side chains of the D1 protein, 
including Ala 344, Asp170, and Glu333 (or His332). They also suggested that, based on weak electron density, D1His337, D1Asp189 (or D1His 190), and D1Tyr73 may also be coordinated to Mn ions of the cluster. Mutagenesis studies already supported the idea that several of these residues could be ligands for Mn ions (Debus 2001; Diner 2001) including those located in the carboxy-terminal domain of the D1 protein (Diner et al. 1991). As in the case of the earlier crystal structure (Zouni et al. 2001), the model of Kamiya and Shen (2003) did not include a $\mathrm{Ca}^{2+}$ bound closely to the Mn cluster.

This was rectified in the crystal structure reported by Ferreira et al. (2004). Anomalous diffraction was collected at a wavelength of $1.89 \AA$ to obtain an electron-density profile for the $\mathrm{Mn}$ ions and at $2.25 \AA$ to locate $\mathrm{Ca}^{2+}$ (at $2.25 \AA$, Ca has an anomalous difference almost four times that of Mn). Again, the electron density attributed to the four Mn ions was "pear shaped," indicative of the $3+1$ organization, and also again, one $\mathrm{Mn}$ was assigned to the small domain and three to the large globular domain, whereas the 2.25 - $\AA$ wavelength map covers one metal ion in the large domain of the native density. From this data, the three $\mathrm{Mn}$ ions $\left(\mathrm{Mn}_{1}, \mathrm{Mn}_{2}\right.$, and $\left.\mathrm{Mn}_{3}\right)$ and the $\mathrm{Ca}^{2+}$ in the large domain were modeled as a cubane organization with bridging oxygens, an organization compatible with the native electron density. The fourth $\mathrm{Mn}$ ion $\left(\mathrm{Mn}_{4}\right)$ located in the small domain was modeled so that it was linked to the cubane by one of its bridging oxygens (see Fig. 4A). Based on values determined by EXAFS measurements, the three Mn-di- $\mu$-oxy-Mn bonds of the cubane were spaced at $2.7 \AA$, whereas the three Mn-di$\mu$-oxy- $\mathrm{Ca}^{2+}$ bonds were spaced at $3.4 \AA$. The dangler Mn was positioned $3.3 \AA$ from the closest $\mathrm{Mn}$ ions of the cubane and $\sim 4 \AA$ from the $\mathrm{Ca}^{2+}$. Although the distances chosen were compatible with distances derived from EXAFS (Yachandra 2002), the predicted numbers of each type of bond were not. Nevertheless, density function calculations (Lundberg and Siegbahn 2004; Sproviero et al. 2006, 2007; Batista et al. 2008) and chemical synthesis of mixed Mn/Ca complexes (Mishra et al. 2005), shown more recently by Kanady et al. (2011) and Mukherjee et al. (2012), suggested that such an organization was chemically feasible despite there being no known similar structure in biology at the time. Moreover, the model provided an important basis for its further refinement by quantum mechanical calculations and for developing detailed mechanisms for the water-splitting reaction leading to dioxygen formation (McEvoy and Brudvig 2004, 2006; Siegbahn 2006, 2008, 2009, 2012; Brudvig 2008; Dau et al. 2008).
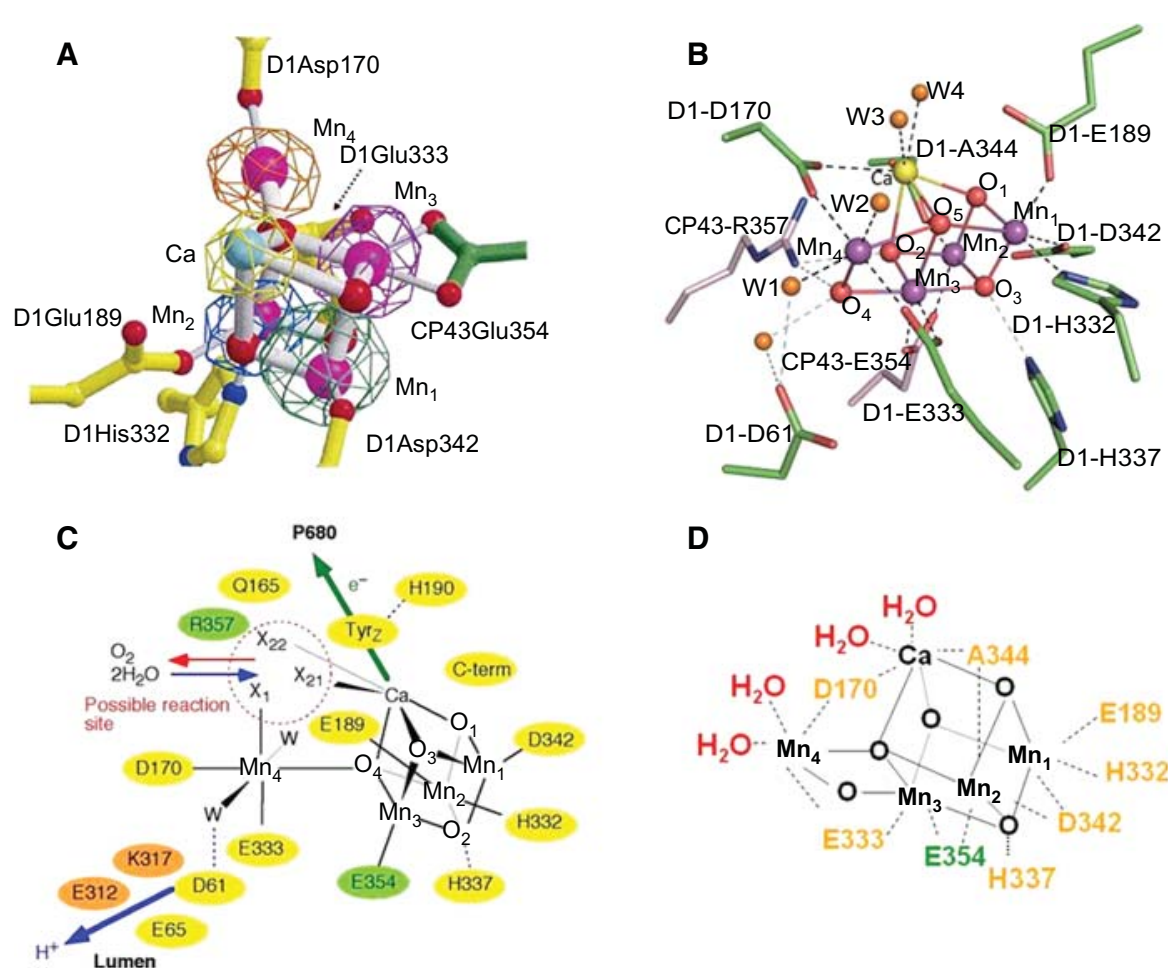

D

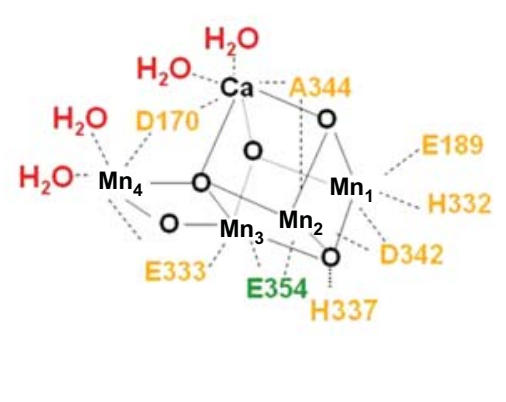

Figure 4. (A) Cubane structural model of the $\mathrm{Mn}_{4} \mathrm{Ca}$ cluster of the $\mathrm{OEC}$ and identification of amino acids within the first coordination sphere deduced from X-ray-diffraction analyses at $3.5 \AA$ by Ferreira et al. (2004). (B) Structure of the $\mathrm{Mn}_{4} \mathrm{CaO}_{5}$ cluster and its ligand environment as determined at a resolution of $1.9 \AA$ by Umena et al. (2011). (C) Schematic view of the OEC published in Ferreira et al. (2004). Residues in D1, D2, and CP43 subunits are shown in yellow, orange, and green, respectively. $X_{11}, X_{21}$, and $X_{22}$ are proposed to be substrate water-binding positions to $\mathrm{Mn}_{4}\left(\mathrm{X}_{11}\right)$ and to $\mathrm{Ca}\left(\mathrm{X}_{21}\right.$ and $\left.\mathrm{X}_{22}\right)$, identified from the position of the nonprotein ligand and coordination pattern of $\mathrm{Mn}$ and $\mathrm{Ca}$ ions. Possible water molecules not visible at 3.5- $\AA$ resolution are suggested and indicated as W. Possible hydrogen bonds are also proposed and shown as light-blue dotted lines. $(D)$ Representation of the $\mathrm{Mn}_{4} \mathrm{CaO}_{5}$ cluster and coordinating ligands determined by Umena et al. (2011). (C, Reprinted, with permission, from Ferreira et al. 2004. (C)AAAS; D, reprinted, with permission, from Umena et al. 2011. (CMacmillan.) 
On the basis of this organization of the metal ions, the $\mathrm{Mn}_{3} \mathrm{CaO}_{4}$ cubane had four protein side chains as potential ligands: D1Asp342, D1Glu189, D1His332, and CP43Glu354. The identification of the glutamate of CP43 as an Mn ligand was a surprise and is a residue of the conserved motif Gly-Gly-Glu-Thr-Met-Arg-PheTrp-Asp, which forms a $3{ }_{10}$ helix in the large extrinsic loop joining the lumenal ends of transmembrane helices $\mathrm{V}$ and $\mathrm{V} 1$ of this protein. In addition to these four apparent protein ligands, it was noted that the carboxy-terminal residue of the D1 protein D1Ala344 is located close to $\mathrm{Ca}^{2+}$ and that D1His337 could be hydrogen bonded to one of the bridging oxo bonds of the cubane. Two side-chain densities were available as ligands (D1Asp170 and D1Glu333) for the "dangler" Mn4 outside the cubane cluster, and it was also suggested that D1Asp61 might also function as a second sphere ligand via a bridging water molecule (see Fig. 4C). A nonprotein electron density in the vicinity of $\mathrm{Mn}_{4}$ and $\mathrm{Ca}^{2+}$ was identified and tentatively modeled as a carbonate ion that formed bridging ligands between the two metals. However, the positioning of this density adjacent to the redox-active D1Tyr161 $\left(\mathrm{Tyr}_{\mathrm{Z}}\right)$ suggested that this could be the site for the binding of substrate water molecules and the formation of an $\mathrm{O}-\mathrm{O}$ bond as diagrammatically shown in Figure 4C, taken from Ferreira et al. (2004). Also located in this potential catalytic site were D1Gln165 and CP43Arg357, which seems to indicate their involvement in a hydrogen-bonding network and therefore having a key role in the deprotonation of the substrate water molecules during the catalytic cycle, whereas D1Asp61 seemed to be strategically located at the mouth of a polar channel that probably functions to facilitate the exit of protons to the lumenal surface.

As mentioned above, the work of Ferreira et al. (2004) also established that D1His190 was in hydrogen-bonding distance to D1Tyr161, as required and predicted for the oxidation of the latter by $\mathrm{P}^{+}$to generate the neutral tyrosine radical (Hoganson and Babcock 1997).

The 3.0- $\AA$ resolution structure reported by Loll et al. (2005) confirmed the subunit and overall amino-acid assignment and side-chain positioning reported by Ferreira et al. (2004), with minor differences within the limitation imposed by the intermediate resolution of both structures. However, as stated above, the improved electron-density map allowed Loll et al. (2005) to correct and extend the original assignment of carotenoid molecules by Ferreira et al. (2004) and to locate several bound lipid molecules. As in the earlier papers from this group (Zouni et al. 2001), the pear-shaped electron density attributed to the metal cluster of the water-splitting site was interpreted as four $\mathrm{Mn}$ ions organized in a $\mathrm{Y}$ shape or $3+1$ arrangement. Based on anomalous diffraction, $\mathrm{Ca}^{2+}$ was placed in a position similar to that proposed by Ferreira et al. (2004), and confirmed by Kargul et al. (2007), whereas the positioning of three of the Mn ions were different to those of Ferreira et al. (2004) but less so to that in the Zouni et al. (2001) model. The fourth Mn ion was assigned to the narrow end of the pear-shaped density in a slightly different position to that of Ferreira et al. (2004) or Zouni et al. (2001). The same amino acids identified as ligands in the crystal structure of Ferreira et al. (2004) were also found by Loll et al. (2005), although there were differences in the precise location in some cases. Importantly, they proposed that the carboxylates of the acidic residues formed bridging ligands among adjacent $\mathrm{Mn}$ ions and therefore more adequately satisfied the coordination requirements of the metal cluster than in the Ferreira et al. (2004) model. However, Loll et al. (2005) emphasized that their model for the OEC was unreliable, in part because of the low resolution of the electron-density map and in part because of radiation damage. Working with the EXAFS group at Berkeley, and before the publication of the Loll et al. crystal structure of 2005, the same group had shown that doses of $\mathrm{X}$ ray that were typical of those used for diffraction analyses caused the reduction of the $\mathrm{Mn}$ cluster and associated structural changes (Yano et al. 2005). This problem of radiation damage occurring at the Mn cluster had also been highlighted by Grabolle et al. (2006). Because of this, doubts were expressed about the cubane model of Ferreira et al. (2004) and several other arrangements of the $\mathrm{Mn}_{4} \mathrm{Ca}$ cluster were postulated based on polarized EXAFS studies conducted by the Berkeley group in collaboration with the X-ray crystallography group in Berlin (Yano et al. 2006). However, a reinterpretation of the polarized EXAFS data by Sproviero and colleagues (2008) at Yale suggested that the cubane model could still be considered as the legitimate organization of the OEC metal cluster.

The uncertainty of the cubane model was dismissed with the most recent $1.9-\AA$ structure from Umena et al. (2011) who showed that at this resolution the electron density of individual metals could be resolved and bridging oxygens inferred (Fig. 4B). The resulting model overall was similar to that proposed by Ferreira et al. (2004) and refined by Sproviero et al. (2006), except an additional oxo bridge was identified, linking the Mn outside the $\mathrm{Mn}_{3} \mathrm{Ca}$ cubane $\left(\mathrm{Mn}_{4}\right)$ to an $\mathrm{Mn}$ ion of the cubane that had been previously proposed by Dau et al. (2008) and Siegbahn (2008).

Four water molecules $(\mathrm{W} 1-\mathrm{W} 4)$ were found to be associated with the $\mathrm{Mn}_{4} \mathrm{Ca}^{2+} \mathrm{O}_{5}$ cluster, of which $\mathrm{W} 1$ and W2 were coordinated to $\mathrm{Mn}_{4}$ and W3 and W4 were coordinated to $\mathrm{Ca}$. No other water molecules were directly associated with the metal cluster, suggesting that some of the four Ws may serve as the substrates for water oxidation, in line with the prediction of Ferreira et al. (2004). All of the amino-acid residues coordinated to the $\mathrm{Mn}_{4} \mathrm{Ca}^{2+} \mathrm{O}_{5}$ cluster were the same as those originally identified by Ferreira et al. (2004) and Loll et al. (2005), but their precise arrangement was now revealed (shown diagrammatically in Fig. 4D). Of these, D1Glu served as a monodentate ligand to $\mathrm{Mn}_{1}$. All of the remaining five carboxylate residues served as bidentate ligands: D1Asp170 as a ligand to $\mathrm{Mn}_{4}$ and Ca, D1Glu333 to $\mathrm{Mn}_{3}$ and $\mathrm{Mn}_{4}, \mathrm{D} 1 \mathrm{Asp} 342$ to $\mathrm{Mn}_{1}$ and $\mathrm{Mn}_{2}$, D1Ala344 to $\mathrm{Mn}_{2}$ and $\mathrm{Ca}$, and CP43Glu354 to $\mathrm{Mn}_{2}$ and $\mathrm{Mn}_{3}$. In addition, D1His332 is coordinated to $\mathrm{Mn}_{1}$. Together with the oxo 
bridges and $\mathrm{Ws}$, these give rise to a saturating ligand environment for the $\mathrm{Mn}_{4} \mathrm{Ca}^{2+} \mathrm{O}_{5}$ cluster, with each of the four Mn ions having six ligands and the $\mathrm{Ca}$ having seven ligands.

In addition to the direct ligands of the $\mathrm{Mn}_{4} \mathrm{Ca}^{2+} \mathrm{O}_{5}$ cluster, Umena et al. (2011) confirmed the Ferreira et al. (2004) finding that D1Asp61, D1His337, and CP43Arg357 are located in the second coordination sphere and may have important roles in maintaining the structure of the metal cluster, in agreement with various recent reports showing the importance of these three residues in maintaining oxygen-evolving activity (Hwang et al. 2007; Debus 2008; Service et al. 2010). Umena et al. (2011) noted that one of the guanidine g-nitrogens of CP43Arg357 is hydrogen bonded to both $\mathrm{O} 2$ and $\mathrm{O} 4$ of the $\mathrm{Mn}_{4} \mathrm{Ca}^{2+} \mathrm{O}_{5}$ cluster, whereas the other is hydrogen bonded to the carboxylate oxygen of D1Asp170 and to that of D1Ala344. They also noted that imidazole e-nitrogen of D1His337 is hydrogen bonded to a bridging oxo, in agreement with the suggestion of Ferreira et al. (2004). Thus, these two residues may function to stabilize the cubane structure of the metal cluster as well as provide partial positive charges to compensate for the negative charges induced by the oxo bridges and carboxylate ligands of the metal cluster. Ferreira et al. (2004) also suggested that D1Asp61 could be hydrogen bonded to a W bridging to Mn4, and Umena et al. (2011) did indeed find that the carboxylate oxygen of D1Asp61 is hydrogen bonded to $\mathrm{W} 1$ and to $\mathrm{O} 4$ indirectly through another W molecule and suggested that this residue may also contribute to stabilizing the metal cluster. Furthermore, as postulated by Ferreira et al. (2004) D1Asp61 seems to be located at the entrance of a proton exit channel, suggesting that this residue may function in facilitating proton exit from the catalytic site and aided by the presence of a bound chloride ion (Murray et al. 2008; Rivalta et al. 2011).

\section{MECHANISM OF WATER OXIDATION}

Although the geometry of the $\mathrm{Mn}_{4} \mathrm{Ca}$ cluster and its ligand field characteristics are now known at a resolution of $1.9 \AA$, there is uncertainty about the S state in which it lies. Because free electrons are generated in the crystal during the collection of X-ray-diffraction data, it is likely that the Mn cluster is reduced to levels lower than that of the $\mathrm{S}_{0}$ state. From quantum mechanical calculations (density functional theory [DFT], QM/MM), Luber et al. (2011) has concluded that the Umena et al. (2011) model most likely corresponds to a mixture of $\mathrm{S}_{0}, \mathrm{~S}_{-1}$, and $\mathrm{S}_{-2}$ oxidation states.

Despite this, the Ferreira et al. (2004) cubane model and its subsequent refinements (Sproviero et al. 2007; Dau et al. 2008; Siegbahn 2008) have provided a basis for developing chemical mechanisms for water oxidation and dioxygen formation. The $\mathrm{Mn}$ ion outside the cubane (Mn4) is adjacent to the $\mathrm{Ca}^{2+}$, and their positioning toward the side chains of several key amino acids, including the redox-active $\mathrm{Y}_{Z}$, suggests that they provide the "catalytic" surface for binding the two substrate $\mathrm{W}$ molecules and their subsequent oxidation. One well-championed mechanism (Messinger et al. 1995; Pecoraro et al. 1998; McEvoy and Brudvig 2004, 2006; Brudvig 2008) suggests that the substrate water, associated with Mn4, is deprotonated during the S-state cycle and converted to a highly electrophilic oxo (see Fig. 5A). This mechanism is dependent on Mn4 being converted to a high oxidation state (possible $\mathrm{Mn}[\mathrm{V}]$ ) during progression to the $\mathrm{S}_{4}$ state just before $\mathrm{O}-\mathrm{O}$ bond formation. The other three $\mathrm{Mn}$ ions also progress to high valency states (Mn[IV]) (e.g., $\mathrm{S}_{0}(\mathrm{Mn}[\mathrm{III}], \mathrm{Mn}[\mathrm{III}]$, $\mathrm{Mn}[\mathrm{III}], \mathrm{Mn}[\mathrm{IV}])$ to $\mathrm{S}_{4}(\mathrm{Mn}[\mathrm{V}], \mathrm{Mn}[\mathrm{IV}], \mathrm{Mn}[\mathrm{IV}]$, $\mathrm{Mn}[\mathrm{IV}])$ and act as a further "oxidizing battery" for the $\mathrm{Mn}(\mathrm{V})$-oxo species in the $\mathrm{S}_{4}$ state (see Fig. 5A). In this way, the reactive oxo is electron deficient, so much so

\section{A Highly electrophilic oxo (or $\mathrm{Mn}^{\prime \mathrm{V}}$ oxyl radical)}

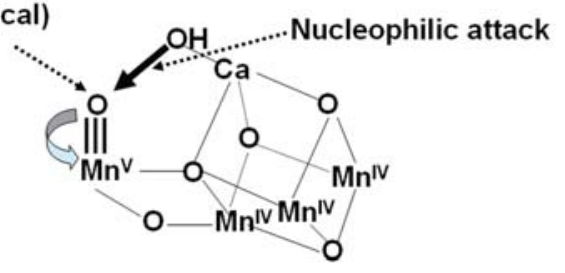

B

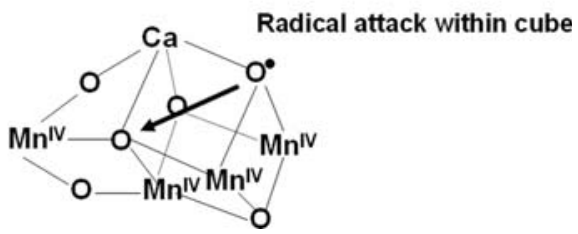

Figure 5. Two different mechanisms for the final step of the $\mathrm{S}$-state cycle when the dioxygen bond of $\mathrm{O}_{2}$ is formed. $(A) \mathrm{Mechanism}$ 1. The very high oxidation state of the Mn-cluster, particularly the $\mathrm{Mn}$ ion outside the $\mathrm{Mn}_{3} \mathrm{CaO}_{5}$ cubane, leads to a high electron deficient oxo (after deprotonation of water molecules during the S-state cycle). Nucleophilic attack by the hydroxide of the second substrate water within the coordination sphere of $\mathrm{Ca}^{2+}$ leads to $\mathrm{O}_{2}$ formation. (B) Mechanism 2. The formation of an oxyl radical on one of the bridging oxygen atoms of the cubane leads to a radical attack of an adjacent oxo-ligand within the $\mathrm{Mn}_{3} \mathrm{CaO}_{4}$ cubane. The fifth oxo linking the Mn outside the cubane to an $\mathrm{Mn}$ of the cubane is not shown. 
that it makes an ideal target for a nucleophilic attack by the oxygen of the second substrate water bound within the coordination sphere of $\mathrm{Ca}^{2+}$ (see Fig. 5A). Deprotonation of the substrate waters would be aided by nearby bases such as CP43 and Arg357 and by the weak Lewis acidity of $\mathrm{Ca}^{2+}$. An alternative mechanism proposed by Siegbahn $(2006,2008,2012)$, based on indepth DFT calculations, suggests that an oxyl radical forms within the $\mathrm{Mn}_{3} \mathrm{CaO}_{4}$ cubane and $\mathrm{O}-\mathrm{O}$ bond formation therefore involves bridging oxo species (see Fig. 5B).

\section{ARTIFICIAL PHOTOSYNTHESIS}

Although some progress has been made in mimicking photosynthesis in artificial systems, researchers have not yet developed components that are both efficient and robust for incorporation into a working system for capturing and storing solar energy in chemical bonds on a large scale, as does natural photosynthesis. To date, the main focus of research has been on designing and synthesizing molecular catalysts that can be linked to a light-driven charge-separation system (Tran et al. 2012). Dyes have been used for the latter, but inorganic semiconductors offer a more realistic and robust approach for providing the oxidizing and reducing potentials necessary to split water and power reductive chemistry.

Insights gleaned from the recent structural determination of PSII have initiated considerable efforts to identify artificial catalytic systems for water oxidation and hydrogen production using solar energy (Eisenberg and Gray 2008). The hydrogen produced could be used directly as a source of energy but could also be used, as it is in natural photosynthesis, to reduce carbon dioxide to other types of fuels such as methane and methanol. The challenge is to have a molecular arrangement such that the artificial catalysts efficiently use light energy to split water and concomitantly provide reducing potential for hydrogen gas production or $\mathrm{CO}_{2}$ reduction. It has been demonstrated that catalysts based on $\mathrm{Mn}$ or $\mathrm{Mn}$ doped with $\mathrm{Ca}$ are capable of water splitting and generating dioxygen (Limberg et al. 1999; Tagore et al. 2008; Najafpour et al. 2010; Zaharieva et al. 2011; Gao et al. 2012). Frei and coworkers (Jiao and Frei 2010) reported that nanostructured manganese oxide clusters supported on mesoporous silica efficiently evolved oxygen in aqueous solution under mild conditions.

Complementing the work on Mn has been the earlier discovery that ruthenium-based catalysts, such as the "blue dimer," that can photooxidize water to dioxygen (Gersten et al. 1982; Liu et al. 2008; Romero et al. 2008), and the recent spectacular work of Duan et al. (2012), which has reported a rationally designed $\mathrm{Ru}-$ based catalyst with an unprecedented turnover rate of 300 per sec, comparable to that of PSII. But perhaps the most practical catalysts for water splitting are based on Co, a relatively abundant element. Kanan and Nocera (2008) have described a self-assembling catalyst composed of $\mathrm{Co}$ and phosphate ions, which can efficiently produce molecular oxygen from water at neutral $\mathrm{pH}$ with a low overpotential akin to that which operates in the OEC of PSII. Dau and colleagues (Risch et al. 2009) have revealed important structural details of this Cobased catalyst and found it to have a molecular organization remarkably similar to the $\mathrm{Mn}_{3} \mathrm{Ca}$ cubane of PSII. More recently, Yin et al. (2010) reported a water-splitting catalyst comprised of a $\mathrm{Co}_{4} \mathrm{O}_{4}$ core stabilized by oxidatively resistant polytungstate ligands that, like the Nocera (Reese et al. 2011) catalyst, is also selfassembling.

Hematite $\left(\alpha-\mathrm{Fe}_{2} \mathrm{O}_{3}\right)$ is a semiconductor that is also capable of photochemically splitting water to molecular oxygen. It has a favorable optical band gap $\left(\mathrm{E}_{\mathrm{g}}=2.2\right.$ $\mathrm{eV}$ ), excellent chemical stability in aqueous environments, natural abundance, and low cost (Sivula et al. 2011). Indeed, hematite has been theoretically predicted to achieve a water oxidation efficiency of $16.8 \%$ (Murphy et al. 2006). However, the reported efficiencies of hematite are lower than this predicted value, mainly due to the very short lifetime of photo-generated charge carriers ( $<10 \mathrm{ps}$ ), short hole-diffusion length $(2-4 \mathrm{~nm})$, slow kinetics, low flat-band potential, and significant reduction in the absorption cross-section at wavelengths approaching the band-gap value. Another fundamental limitation of the hematite system is the need for externally applied bias because the conduction band of hematite is lower than the potential required to reduce protons to hydrogen. Nevertheless, it is a system that is receiving considerable attention at the present time (Tran et al. 2012).

The next step will be to couple these oxygen-producing systems to another catalyst that will use the protons and high-energy electrons derived from the water-splitting reaction to produce hydrogen gas or reduce carbon dioxide. In the case of the former, considerable progress is being made (Wang et al. 2012), in part by mimicking the natural hydrogenase enzymes found in a wide variety of microorganisms (Tran et al. 2010). In addition, a number of inorganic catalysts have been identified with activities that are almost as efficient as platinum. One such class of catalysts are based on sulfides of Mo and W (Zong et al. 2011; Merki and Hu 2011) and another is an alloy composed of Ni, Mo, and Zn (Reece et al. 2011). Identifying catalysts for the reduction of carbon dioxide, however, is more difficult because multielectron reactions are required and the emergence of catalysts for generating useful carbon fuels will require considerable effort (Fujita 2000; Arakawa et al. 2001).

The most successful coupling of catalysts using a semiconductor for light capture and charge separation was reported by Nocera and colleagues (Reece et al. 2011). They used a triple-junction amorphous Si wafer as the semiconductor, the CoPi catalyst for water splitting, and the NiMoZn alloy for the cathodic hydrogen-producing catalyst as shown in Figure 6. This latest discovery is a major step toward the development of an efficient, robust, low-cost, and scalable photocatalytic device for water splitting to generate molecular hydrogen using solar energy. 


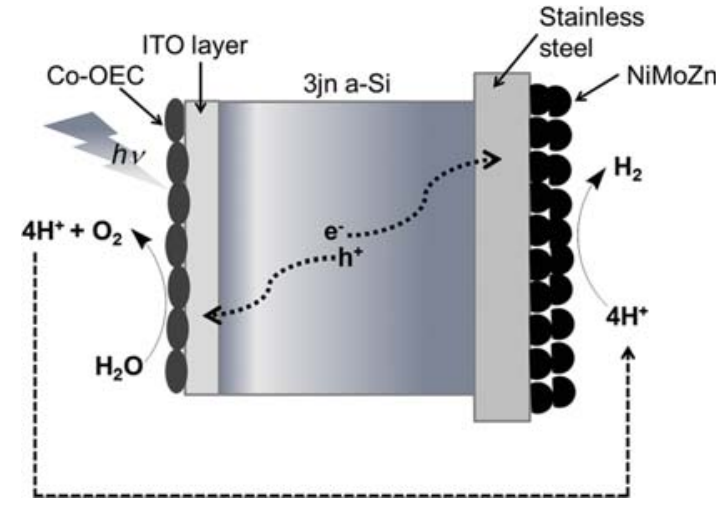

Figure 6. Diagramatic representation of Nocera's (Reece et al. 2011) photocatalytic device for water splitting, consisting of a triple n-junction amorphous silicon wafer, Co-based oxygenevolving catalyst (OEC), and a NiMoZn $\mathrm{H}_{2}$-evolving catalyst as reported in Reece et al. (2011).

\section{CONCLUSION}

The determination of the structure of PSII has provided strong hints of how nature conducts the remarkable chemistry of water splitting. This new information now provides a blueprint for scientists to seriously consider constructing catalysts that mimic the natural system and provide new technologies to address the energy $/ \mathrm{CO}_{2}$ problem that humankind must solve. After all, there is no shortage of water for this reaction, and the energy content of sunlight falling on our planet well exceeds our needs.

\section{ACKNOWLEDGMENTS}

This work was supported with grants from the European Commission (SOLHYDROMICS project grant nos. 227192 and FP-7-Energy-2008-FET), the Biotechnology and Biological Sciences Research Council, and the Engineering and Physical Sciences Research Council.

\section{REFERENCES}

Arakawa H, Aresta M, Armor JN, Barteau MA, Beckman EJ, Bell AT, Bercaw JE, Creutz C, Dinjus E, Dixon DA, et al. 2001. Catalysis research of relevance to carbon management: Progress, challenges, and opportunities. Chem Rev 101: 953-996.

Barber J. 1987. Photosynthetic reaction centres: A common link. Trends Biochem Sci 12: 321-326.

Barber J. 2003. Photosystem II: The engine of life. Q Rev Biophys 36: $71-89$.

Barber J, Andersson B. 1992. Too much of a good thing: Light can be bad for photosynthesis. Trends Biochem Sci 17: 61-66.

Barber J, Archer MD. 2001. P680, the primary electron donor of PSII. J Photochem Photobiol A 142: 97-106.

Batista VS, Sproviero EM, Gascon JA, McEvoy JP, Brudvig GW. 2008. Computational studies of the $\mathrm{O}_{2}$-evolving complex of photosystem II and biomimetic oxo manganese complexes. Coord Chem Rev 252: 395-415.
Brudvig GW. 2008. Water oxidation chemistry of photosystem II. Philos Trans R Soc Lond B Biol Sci 363: 1211-1218.

Dau H, Grundmeier A, Loja P, Haumann M. 2008. On the structure of the manganese complex of photosystem II: Extended-range EXAFS data and specific atomic-resolution models for four S-states. Philos Trans R Soc Lond B 363: 1237-1243.

Debus RJ. 2001. Amino acid residues that modulate the properties of tyrosine $\mathrm{Y}-\mathrm{Z}$ and the manganese cluster in the water oxidizing complex of photosystem II. Biochim Biophys Acta 1503: $164-186$.

Debus RJ. 2008. Protein ligation of the photosynthetic oxygenevolving center. Coord Chem Rev 252: 244-258.

De Las Rivas J, Balsera M, Barber J. 2004. Evolution of oxygenic photosynthesis: Genome-wide analysis of the OEC extrinsic proteins. Trends Plant Sci 9: 18-25.

Diner BA. 2001. Amino acid residues involved in the coordination and assembly of the manganese cluster of photosystem II. Proton-coupled electron transport of the redox-active tyrosines and its relationship to water oxidation. Biochim Biophys Acta 1503: 147-163.

Diner BA, Nixon PJ, Farchaus JW. 1991. Site-directed mutagenesis of photosynthetic reaction centers. Curr Opin Struct Biol 1: $546-554$.

Duan L, Bogoglian F, Mandal S, Stewart B, Privalot T, Llobet A, Sun L-C. 2012. A molecular ruthenium catalyst with wateroxidation activity comparable to that of photosystem II. Nat Chem 4: 418-423.

Durrant JR, Klug DR, Kwa SLS, van Grondelle RV, Porter G, Klug DR. 1995. A multimer model for P680, the primary electron donor of photosystem II. Proc Natl Acad Sci 92: 4798-4802.

Eisenberg E, Gray HB. 2008. Preface to making oxygen. Inorg Chem 47: 1697-1699.

Faller P, Debus RJ, Brettel K, Sugiura M, Rutherford AW, Boussac A. 2001. Rapid formation of the stable tyrosyl radical in photosystem II. Proc Natl Acad Sci 98: 14368-14373.

Ferreira KN, Iverson TM, Maghlaoui K, Barber J, Iwata S. 2004. Architecture of the photosynthetic oxygen-evolving center. Science 303: $1831-1838$.

Fujita E. 2000. Carbon dioxide reduction. In McGraw-Hill Yearbook of Science \& Technology (ed. Licker MD), pp. 71-74. McGraw-Hill Book Co, New York, NY.

Gao Y, Crabtree RH, Brudvig GW. 2012. Water oxidation catalyzed by the tetranuclear $\mathrm{Mn}$ complex: $\left[\mathrm{Mn}_{4}^{\mathrm{IV}} \mathrm{O}_{5} \text { (terpy }\right)_{4}$ $\left.\left(\mathrm{H}_{2} \mathrm{O}\right)_{2}\right]\left(\mathrm{ClO}_{4}\right)_{6}$. Inorg Chem 51: 4043-4050.

Gersten SW, Samuels GJ, Meyer TJ. 1982. Catalytic oxidation of water by an oxo-bridged ruthenium dimer. J Amer Chem Soc 104: 4029-4030.

Govindjee, van Rensen JJS. 1993. Photosystem II reaction centers and bicarbonate. In The Photosynthetic Reaction Center (ed. Deisenhofer JB, Norris J), pp. 357-389. Academic Press, San Diego.

Grabolle M, Haumann M, Muller C, Liebisch P, Dau H. 2006. Rapid loss of structural motifs in the manganese complex of oxygenic photosynthesis by X-ray irradiation at $10-300 \mathrm{~K}$. J Biol Chem 281: 4580-4588.

Guskov A, Kern J, Gabdulkhakov A, Broser M, Zouni A, Saenger W. 2009. Cyanobacterial photosystem II at $2.9 \AA$ resolution: Role of quinones, lipids, channels and chloride. Nat Struct Mol Biol 16: 334-342.

Hankamer B, Barber J, Boekema EJ. 1997. Structure and membrane organisation of PSII in green plants. Annu Rev Plant Phys Mol Biol 48: 641-671.

Hankamer B, Morris EP, Nield J, Gerle C, Barber J. 2001a. Three-dimensional structure of photosystem II core dimer of higher plants determined by electron microscopy. J Struct Biol 135: 262-269.

Hankamer B, Morris EP, Nield J, Carne A, Barber J. 2001b. Subunit positioning and transmembrane helix organisation in the core dimer of photosystem II. FEBS Lett 504: 142-151.

Hasegawa K, Ono TA, Inoue Y, Kusunoki M. 1999. Spin-exchange interactions in the $\mathrm{S}_{2}$-state manganese tetramer in 
photosynthetic oxygen-evolving complex deduced from $\mathrm{g}=$ 2 multiline EPR signal. Chem Phys Letts 300: 9-19.

Hienerwadel R, Berthomieu C. 1995. Bicarbonate binding to the non-heme iron of photosystem II investigated by Fourier transform infrared difference spectroscopy and 13C-labeled bicarbonate. Biochemistry 34: 16288-16297.

Hoganson CW, Babcock GT. 1997. A metalloradical mechanism for the generation of oxygen from water in photosynthesis. Science 277: 1953-1956.

Holzwarth AR, Muller MG, Rees M, Nowaczyk M, Sander J, Rogner M. 2006. Kinetics and mechanism of electron transfer in intact photosystem II and in isolated reaction centers: Pheophytin is the primary acceptor. Proc Natl Acad Sci 103: 6895-6900.

Hwang HJ, Dilbeck P, Debus RJ, Burnap RL. 2007. Mutation of arginine 357 of the CP43 protein of photosystem II severely impairs the catalytic S-state cycle of the $\mathrm{H}_{2} \mathrm{O}$ oxidation complex. Biochemistry 46: 11987-11997.

Jiao F, Frei H. 2010. Nanostructure manganese oxide clusters supported on mesoporous silica as efficient oxygen-evolving catalysts. Chem Commun 46: 2920-2922.

Kamiya N, Shen JR. 2003. Crystal structure of oxygen-evolving photosystem II from Thermosynechococcus vulcanus at 3.7-Å resolution. Proc Natl Acad Sci 100: 98-103.

Kanady S, Tsui E, Day M, Agapie T. 2011. A synthetic model of the $\mathrm{Mn}_{3} \mathrm{Ca}$ subsite of the oxygen-evolving complex in photosystem II. Science 333: 733-736.

Kanan MW, Nocera DG. 2008. In situ formation of an oxygenevolving catalyst in neutral water containing phosphate and $\mathrm{Co}_{2}^{+}$. Science 321: 1072-1075.

Kargul J, Maghlaoui K, Murray JW, Deak Z, Boussac A, Rutherford AW, Vass I, Barber J. 2007. Purification, crystallization and X-ray diffraction analyses of the T. elongatus PSII core dimer with strontium replacing calcium in the oxygen-evolving complex. Biochim Biophys Acta 1767: 404-413.

Kashino Y, Takahashi T, Inoue-Kashino N, Ban A, Yohei Ikeda Y, Satoh K, Sugiura M. 2007. Ycf12 is a core subunit in the photosystem II complex. Biochim Biophys Acta 1767: 12691275.

Kok B, Forbush B, McGloin M. 1970. Cooperation of charges in photosynthetic $\mathrm{O}_{2}$ evolution. 1. A linear four step mechanism. Photochem Photobiol 11: 457-475.

Limberg J, Vrettos JS, Liable-Sands LM, Rheingold AL, Crabtree RH, Brudvig GW. 1999. A functional model for O-O bond formation by the $\mathrm{O}_{2}$-evolving complex in photosystem II. Science 283: 1524-1527.

Liu F, Concepcion JJ, Jurss JW, Cardolaccia T, Templeton JL, Meyer TJ. 2008. Mechanisms of water oxidation from the blue dimer to photosystem II. Inorgan Chem 47: 1727-1752.

Loll B, Kern J, Saenger W, Zouni A, Biesiadka J. 2005. Towards complete cofactor arrangement in the $3.0 \AA$ resolution structure of photosystem II. Nature 438: 1040-1044.

Luber S, Rivalta I, Umena Y, Kawakami K, Shen J-R, Kamiya N, Brudvig GW, Batista VS. 2011. $\mathrm{S}_{1}$-state model of the $\mathrm{O}_{2}$ evolving complex of photosystem II. Biochemistry 50: 63086311.

Lundberg M, Siegbahn PEM. 2004. Theoretical investigations of the structure and mechanism of the oxygen-evolving complex in PSII. Phys Chem Chem Phys 6: 4772-4780.

McEvoy JP, Brudvig GW. 2004. Structure-based mechanism of photosynthetic water oxidation. Phys Chem Chem Phys 6: $4754-4763$.

McEvoy JP, Brudvig GW. 2006. Water-splitting chemistry of photosystem II. Chem Rev 106: 4455-4483.

Merki D, Hu X. 2011. Recent developments of molybdenum and tungsten sulfides as hydrogen evolution catalysts. Energy Environ Sci 4: 3878-3888.

Messinger J, Badger M, Wydrzynski T. 1995. Detection of one slowly exchanging substrate water molecule in the $\mathrm{S}_{3}$ State of Photosystem II. Proc Natl Acad Sci 92: 3209-3213.

Michel H, Deisenhofer J. 1988. Relevance of the photosynthetic reaction center of purple bacteria to the structure of photosystem II. Biochemistry 27: 1-7.
Mishra A, Wernsdorfer W, Abboud KA, Christou G. 2005. The first high oxidation state manganese-calcium cluster: Relevance to the water oxidizing complex of photosynthesis. Chem Commun 2005: 54-56.

Mukherjee S, Stull JA, Yano J, Stamatatos T, Pringouri K, Stich TA, Abboud KA, Britt RD, Yachandra VK, Christou G. 2012. Synthetic model of the asymmetric $\left[\mathrm{Mn}_{3} \mathrm{CaO}_{4}\right]$ cubane core of the oxygen-evolving complex of photosystem II. Proc Natl Acad Sci 109: 2257-2262.

Murphy AB, Barnes PRF, Randeniya LK, Plumb IC, Grey IE, Horne MD, Glasscock JA. 2006. Efficiency of solar water splitting using semiconductor electrodes. Int J Hydrogen Energy 31: 1999.

Murray JW, Barber J. 2007. Structural characteristics of channels and pathways in Photosystem II including the identification of an oxygen channel. J Struct Biol 159: 228-237.

Murray JW, Duncan J, Barber J. 2006. CP43-like chlorophyll binding proteins: Structural and evolutionary implications. Trends Plant Sci 11: 152-158.

Murray JW, Maghlaoui K, Kargul J, Ishida N, Lai T-L, Rutherford AW, Sugiura M, Boussac A, Barber J. 2008. X-ray crystallography identifies two chloride binding sites in the oxygen evolving centre of photosystem II. Energy Environ Sci 1: $161-166$.

Najafpour MM, Ehrenberg T, Wiechen M, Kurz P. 2010. Calcium manganese(III) oxides $\left(\mathrm{CaMn}_{2} \mathrm{O}_{4} \cdot x \mathrm{H}_{2} \mathrm{O}\right)$ as biomimetic oxygen-evolving catalysts Angew Chem 49: 2233-2237.

Pecoraro VL, Baldwin MJ, Caudle MT, Hsieh W-Y, Law NA. 1998. A proposal for the water oxidation in Photosystem II. Pure and Appl Chem 70: 925-929.

Peloquin JM, Campbell KA, Randall DW, Evanchik MA, Pecoraro VL, Armstrong WH, Britt RD. 2000. 55Mn ENDOR of the $\mathrm{S}_{2}$-state multiline EPR signal of photosystem II: Implications on the structure of the tetranuclear Mn cluster. $J \mathrm{Am}$ Chem Soc 122: 10926-10942.

Reece SY, Hamel JA, Sung K, Jarvi TD, Esswein AJ, Pijpers JJH, Nocera DG. 2011. Wireless solar water splitting using silicon-based semiconductors and earth-abundant catalysts. Science 334: 645-648.

Rhee K-H, Morris EP, Zheleva D, Hankamer B, Kühlbrandt W, Barber J. 1997. Two-dimensional structure of plant photosystem II at $8 \AA$ resolution. Nature 389: 522-526.

Rhee K-H, Morris EP, Barber J, Kühlbrandt W. 1998. Threedimensional structure of the photosystem II reaction centre at $8 \AA$ resolution. Nature 396: $283-286$.

Risch M, Khare V, Zaharieva I, Gerencser L, Chernev P, Dau H. 2009. Cobalt-oxo core of a water-oxidizing catalyst film. J Am Chem Soc 131: 6936-6937.

Rivalta I, Amin M, Luber S, Vassiliev S, Pokhrel R, Umena Y, Kawakami K, Shen J-R, Kamiya N, Bruce D, et al. 2011. Structural-functional role of chloride in photosystem II. Biochemistry 50: 6312-6315.

Romero I, Rodriguez M, Sens C, Mola J, Kollipara MR, Francas L, Mas-Marza E, Escriche L, Llobet A. 2008. Ru complexes that can catalytically oxidize water to molecular dioxygen. Inorgan Chem 47: 1824-1834.

Rutherford AW. 1989. Photosystem II: The water splitting enzyme. Trends in Biochem Sci 14: 227-232.

Schubert WD, Klukas O, Saenger W, Witt HT, Fromme P, Krauss N. 1998. A common ancestor for oxygenic and anoxygenic photosynthetic systems: A comparison based on the structural model of Photosystem I. J Mol Biol 280: 297-341.

Service RJ, Hillier W, Debus RJ. 2010. Evidence from FTIR difference spectroscopy of an extensive network of hydrogen bonds near the oxygen-evolving $\mathrm{Mn}_{4} \mathrm{Ca}$ cluster of photosystem II involving D1-Glu65, D2-Glu312, and D1-Glu329. Biochemistry 49: 6655-6669.

Siegbahn PEM. 2006. O-O bond formation in the $\mathrm{S}_{4}$-state of the oxygen evolving complex in photosystem II. Chem-Eur J 12: 9217-9237.

Siegbahn PEM. 2008. A structure-consistent mechanism for dioxygen formation in photosystem II. Chemistry 14: 82908302 . 
Siegbahn PEM. 2009. Structures and energetics for $\mathrm{O}_{2}$ formation in photosystem II. Acc Chem Res 42: 1871-1880.

Siegbahn PEM. 2012. Mechanisms for proton release during water oxidation in the $\mathrm{S}_{2}$ to $\mathrm{S}_{3}$ and $\mathrm{S}_{3}$ to $\mathrm{S}_{4}$ transitions in photosystem II. Phys Chem Chem Phys 14: 4849-4856.

Sivula K, Le Formal F, Gratzel M. 2011. Solar water splitting: Progress using hematite $\left(\alpha-\mathrm{Fe}_{2} \mathrm{O}_{3}\right)$ photoelectrodes. ChemSusChem 4: 432-449.

Sproviero EM, Gascon JA, McEvoy JP, Brudvig GW, Batista VS. 2006. QM/MM models of the $\mathrm{O}_{2}$-evolving complex of photosystem II. J Chem Theory Comput 2: 1119-1134.

Sproviero EM, Gascon JA, McEvoy JP, Brudvig GW, Batista VS. 2007. Quantum mechanics/molecular mechanics structural models of the oxygen-evolving complex of photosystem II. Curr Opin Struct Biol 17: 173-180.

Sproviero EM, Gascon JA, McEvoy JP, Brudvig GW, Batista VS. 2008. Quantum mechanics/molecular mechanics study of the catalytic cycle of water splitting in photosystem II. $J$ Am Chem Soc 130: 3428-3442.

Stewart DH, Brudvig GW. 1998. Cytochrome $b_{559}$ of photosystem II. Biochim Biophys Acta 1367: 63-87.

Tagore R, Crabtree RH, Brudvig GW. 2008. Oxygen evolution catalysis by a dimanganese complex and its relation to photosynthetic water oxidation. Inorg Chem 47: 18151823.

Tran PD, Artero V, Fontecave M. 2010. Water electrolysis and photoelectrolysis on electrodes engineered using biological and bio-inspired molecular systems. Energy Environ Sci 3: 727-747.

Tran PD, Wong LH, Barber J, Loo JSC. 2012. Recent advances in hybrid photocatalysts for solar fuel production. Energy Environ Sci 5: 5902-5918.
Umena Y, Kawakami K, Shen JR, Kamiya N. 2011. Crystal structure of oxygen-evolving photosystem II at a resolution of 1.9 angstrom. Nature 473: 55-65.

Wang M, Chen L, Sun L. 2012. Recent progress in electrochemical hydrogen production with earth-abundant metal complexes as catalysts. Energy Environ Sci 5: 6763-6778.

Yachandra VK. 2002. Structure of the Mn complex in photosystem II: Insights from X-ray spectroscopy. Phil Trans Roy Soc Lond B 357: 1347-1358.

Yano J, Kern J, Irrgang K-D, Latimer MJ, Bergmann U, Glatzel P, Pushkar Y, Biesiadka J, Loll B, Sauer K, et al. 2005. X-ray damage to the $\mathrm{Mn}_{4} \mathrm{Ca}$ complex in photosystem II crystals: A case study for metallo-protein X-ray crystallography. Proc Natl Acad Sci 102: 12047-12052.

Yano J, Kern J, Sauer K, Latimer MJ, Pushkar Y, Biesiadka J, Loll B, Saenger W, Messinger J, Zouni A, et al. 2006. Where water is oxidised to dioxygen: Structure of the photosynthetic $\mathrm{Mn}_{4} \mathrm{Ca}$ cluster. Science 314: 821-825.

Yin Q, Tan JM, Besson C, Geletii YV, Musaev DG, Kuznetsov AE, Luo Z, Hardcastle KI, Hill CL. 2010. A fast soluble carbon-free molecular water oxidation catalyst based on abundant metals. Science 328: 342-345.

Zaharieva I, Najafpour MM, Wiechert M, Haumann M, Kurz P, Dau H. 2011. Synthetic manganese-calcium oxides mimic the water-oxidizing complex of photosynthesis functionally and structurally. Energy Environ Science 4: 2400-2408.

Zong X, Han J, Ma G, Yan H, Wu G, Li C. 2011. Photocatalytic $\mathrm{H} 2$ evolution on CdS loaded with $\mathrm{WS}_{2}$ as cocatalyst under visible light irradiation. J Phys Chem C 115: 12202-12208.

Zouni A, Witt HT, Kern J, Fromme P, Krauss N, Saenger W, Orth P. 2001. Crystal structure of photosystem II from Synechococcus elongatus at 3.8 Å resolution. Nature 409: 739-743. 


\section{$\$_{\text {CSH }}^{\infty}$ Cold Spring Harbor Symposia SYMPOSIA}

\section{Photosystem II: The Water-Splitting Enzyme of Photosynthesis}

J. Barber

Cold Spring Harb Symp Quant Biol 2012 77: 295-307 originally published online December 12, 2012

Access the most recent version at doi:10.1101/sqb.2012.77.014472

References This article cites 86 articles, 16 of which can be accessed free at: http://symposium.cshlp.org/content/77/295.full.html\#ref-list-1

\section{License}

Email Alerting Service the box at the top right corner of the article or click here. 